Research Article

\title{
Mapping the residual tidal ellipse from Vung Tau-Bac Lieu, Viet Nam by using a numerical model in curvilinear coordinate
}

\author{
Tran Thi Kim ${ }^{1,2,4}$, Nguyen Khac Thanh Long ${ }^{3,4}$, Nguyen Thi Thu Hong', Nguyen Ky \\ Phung ${ }^{5}$, Nguyen Thi Bay ${ }^{3,4^{*}}$
}

${ }^{1}$ Ho Chi Minh City University of Natural Resources and Environment; ttkim@hcmunre.edu.vn

${ }^{2}$ Institute of Environment and Natural Resources, Vietnam National University Ho Chi Minh City; ttkim@hcmunre.edu.vn

${ }^{3}$ University of Technology; ntbay@hcmut.edu.vn

${ }^{4}$ Vietnam National University Ho Chi Minh City; ntbay@hcmut.edu.vn

${ }^{5}$ Institute of Computational Science and Technology; kyphungng@gmail.com

*Correspondence: ntbay@hcmut.edu.vn; Tel.: +84-902698585

Received: 12 June 2021; Accepted: 21 July 2021; Published: 25 August 2021

\begin{abstract}
Tidal currents are often the dominant source of current variability and play an important role in shaping coastal bottom topography. In this paper, the authors applied a hydraulic model in curvilinear coordinates to calculate 4 main tidal constituents, namely $\mathrm{K}_{1}, \mathrm{O}_{1}, \mathrm{M}_{2}$ and $\mathrm{S}_{2}$ in a region from Vung Tau-Bac Lieu, Viet Nam. The hydraulic model with the two-dimensional orthogonal curvilinear grid has the advantage of increasing the accuracy of the results at the domain boundary. The numerical method of this model derives from the solution of the Reynolds system of equations averaged over depths in the curvilinear coordinate systems. The model verification is implemented based on the equilibrium of the tidal currents of energy. The result of this model is used to map ellipse constituents and help understand more about the tidal deposition from Vung Tau to Bac Lieu, Viet Nam. The results recorded that the residual tidal ellipse $\mathrm{M}_{2}$ from Vung TauBac Lieu, the greatest ellipses are $\mathrm{M}_{2}$, followed by the tidal constituents $\mathrm{K}_{1}, \mathrm{O}_{1}$ and $\mathrm{S}_{2}$. This rotation of the ellipse is almost the same with clockwise.
\end{abstract}

Keywords: Ellipse constituents; Tidal constituents; Numerical model; Curvilinear coordinates.

\section{Introduction}

The tidal regime at a certain location is determined according to the period of tidal fluctuations. There are two basic types of tides, semi-diurnal and diurnal. With a semidiurnal tide, there are two high tides and two low tides in a day, while a diurnal tide has only one rise and one low tide in a day Tides propagate in the hydrosphere as long waves, with periods of many hours, wavelengths thousands of kilometers, and small amplitudes (compared to wavelengths) and are called tidal constituents. The properties of the component tidal constituents depend on the magnitude and period of gravitational change between the earth's surface, the moon and the sun. There are 396 significant tidal components, the basic tidal constituents are: semi-diurnal constituents (symbols $\mathrm{M}_{2}$ and $\mathrm{S}_{2}$ ), diurnal constituents (symbols $\mathrm{O}_{1}$ and $\mathrm{K}_{1}$ ) [1]. For each tidal constituent the tip of the current velocity vector describes an ellipse. Within each period of the respective tidal constituent a full rotation is executed [2]. 
The studies of tidal characteristics, particularly, tidal ellipse has been studied by many researchers. [3] calculated and compared the tidal flow results from the model and the observation for New Zealand region. The results showed that the $\mathrm{M}_{2}$ tidal constituent is the dominant component of currents in this region, and the model gives the best results for this constituent. The tidal ellipse of $\mathrm{M}_{2}$ constituent shows the strongest tidal currents in Cook Strait, near Stewart Island and parts of Hauraki Bay. [4] applied a two-dimensional vertically integrated hydrodynamic model to simulate the hydrodynamics in the Tagus estuary and the model developed from the SIMSYS2D model. The result of the model was the tidal hydrodynamic regime of the Tagus estuary by analysing the amplitude, phase, tidal ellipse parameters of both semi-diurnal and diurnal constituents. [5] studied the characteristics of tidal current and tidal residual current in Chunsu Bay, Yellow Sea, Korea based on numerical modeling experiments - ECOM3D. The model results have been verified through measurement data, amplitude and phase analysis of 4 main tidal constituents $\left(\mathrm{M}_{2}, \mathrm{~S}_{2}, \mathrm{~K}_{1}\right.$ and $\left.\mathrm{O}_{1}\right)$ of current velocity and sea level. [6] extracted highfrequency tidal variability from HF Radar Data in the northwestern Bay of Bengal and analyzed tidal harmonic by using the $T_{-}$Tide tool. The constituents $\mathrm{S}_{4}, \mathrm{MS}_{4}$ and $\mathrm{M}_{3}\left(\mathrm{M}_{4}\right.$, $2 \mathrm{SM}_{6}$ and $\mathrm{M}_{6}$ ) at nearshore location (offshore) was identified, which are due to the nonlinear interaction of tidal currents with bathymetry. In 2019, Ahmed and Siddiqa used the Tide and Wave Recorder TWR-2050 along with Flow Quest 600 and ADCP to record tidal levels in coast of Karrachi, Pakistan. The ellipses were used to analyze the tidal current characteristics. In the study region, semi-diurnal tide prevails [7].

In Viet Nam, [8] published a paper in 2007 which calculated tidal currents in the North Danger Reef by using finite element method (FEM) with shallow water equations, mainly continuity and momentum equations to partially solve the problems of bottom topography, boundary conditions, etc. using the finite difference method (FDM). The result shows the characteristics of ellipse for 4 main tidal constituents $\left(\mathrm{K}_{1}, \mathrm{O}_{1}, \mathrm{M}_{2}, \mathrm{~S}_{2}\right)$ and tidal currents. [9] calculated the tidal wave propagation along the Mekong Deltaic coast by using Delft3SFLOW model for the hydrodynamic regime and the astronomical phases and amplitudes were analyzed, using Delft3D-TIDE tool. The tidal ellipses of the $\mathrm{M}_{2}$ semi-diurnal constituent show strong currents occurring on the eastern coast of the Mekong Delta, while weak currents occur near the western coast. The residual current increased in the southeastern of the shallow area of the Mekong Delta is strongest along the Ca Mau peninsula up to about $10-15 \mathrm{~cm} / \mathrm{s}$. In addition, a geographical distribution map of tidal characteristics in the entire East Sea Viet Nam has been developed.

For nearshore areas, curvilinear coordinate models show many advantages. Because the velocity field is calculated on a curved grid (which is usually built along shorelines), the simulation results in areas with complex topography are better. Furthermore, the hydraulic model with the two-dimensional orthogonal curvilinear grid has the advantage of increasing the accuracy of the results at the domain boundary. In general, the studies show that tidal currents in the shallow waters are influenced by topography. This study focuses on building an ellipse map of tidal currents from Vung Tau to Bac Lieu where is strongly influenced by the semi-diurnal tidal regime by a curvilinear coordinate model. In the nearshore, the friction is calculated as a matrix inversely proportional to the depth. The results of ellipse for 4 main constituents $\mathrm{K}_{1}, \mathrm{O}_{1}, \mathrm{M}_{2}$ and $\mathrm{S}_{2}$ are essential information about the semi-diurnal tidal characteristics in this region.

\section{Material and method}

\subsection{Material}

The Southern region, Viet Nam is affected by two different tidal systems originating from the East Sea and the Southwest Sea. Therefore, the tidal regime in the coastal strip 
from Vung Tau to Ca Mau Cape is irregular semi-diurnal tide. In this study, ellipses will be established for this semi-diurnal zone. The study area is the coastal area from Vung Tau to Bac Lieu (Figure 1a), geographically located from $106.009^{\circ}$ to $106.84^{\circ}$ East longitude and $8.91^{\circ}$ to $9,63^{\circ}$ North latitude.

The domain consists of four boundaries: three liquid boundaries (Boundary 2, 3 and 4) are the East Sea boundaries; the solid boundary is the coastline of the Hau Estuary (Boundary 1), in which, there are two river boundaries (Figure 1b). A computational mesh (Figure 1b) is a curved perpendicular the computational mesh with a mesh size of $130 \mathrm{x}$ 155 cells with $d_{x}, d_{y}$ in the range of 300 meters to 500 meters.

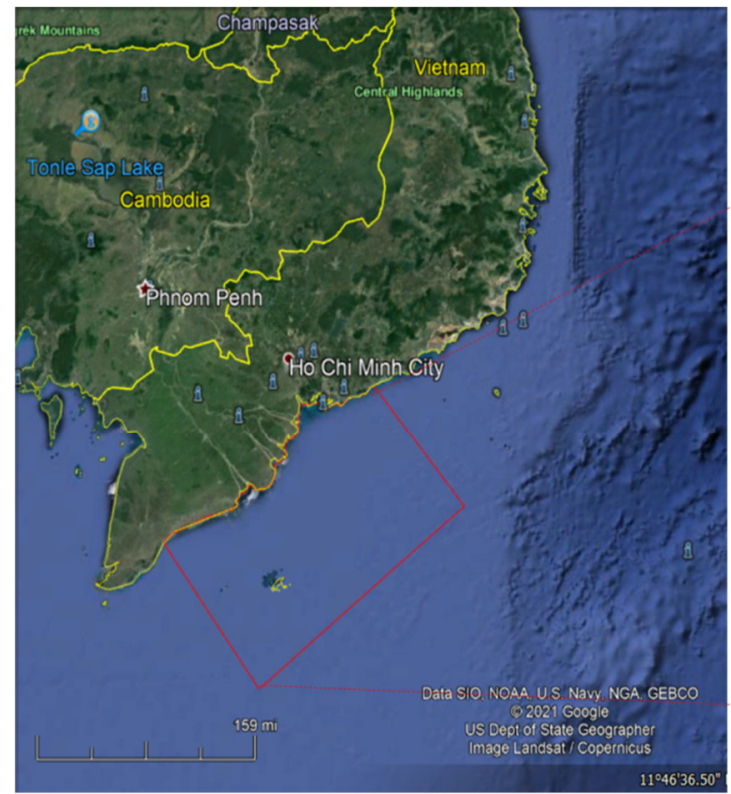

(a)

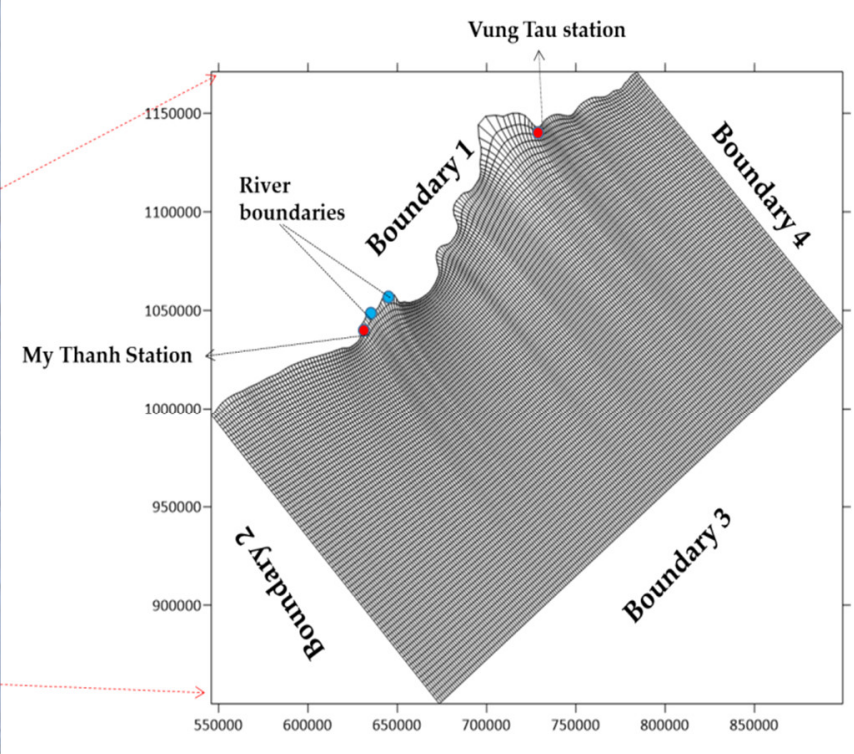

(b)

Figure 1. Study area.

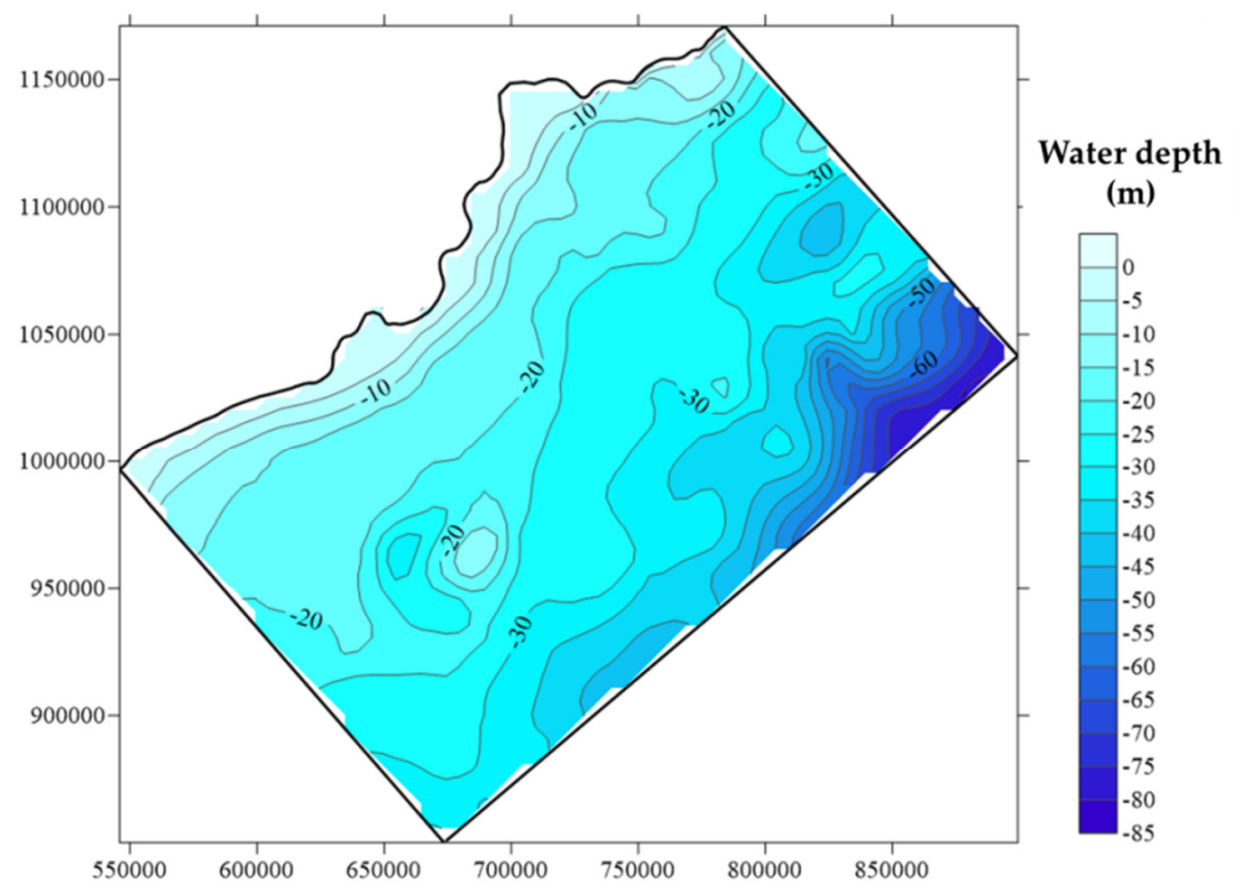

Figure 2. Topography. 
Topography: The topographic data (Figure 2) is collected in 2010 from Southern Institute of Water Resources Research, Viet Nam (SIWRR). The parameters in the model are set up: Time step (dt): $72 \mathrm{~s}$, Coriolis: $2.4096 \times 10^{-5}$, Sigma $7.26 \times 10^{-5}\left(\mathrm{~K}_{1}\right), 6.76 \times 10^{-5}$ $\left(\mathrm{O}_{1}\right), 14.05 \times 10^{-5}\left(\mathrm{M}_{2}\right), 14.54 \times 10^{-5}\left(\mathrm{~S}_{2}\right)$, Tidal constituent period: $8614 \mathrm{~s}\left(\mathrm{~K}_{1}\right), 92950 \mathrm{~s}$ $\left(\mathrm{O}_{1}\right), 44714 \mathrm{~s}\left(\mathrm{M}_{2}\right), 43200 \mathrm{~s}\left(\mathrm{~S}_{2}\right)$. The density of sea water: $1026 \mathrm{~kg} / \mathrm{m}^{3}$.

The friction bed coefficients for four tidal constituents were set up changing the water depth with the range of 0.026 to 0.058 (Figure 3 ).

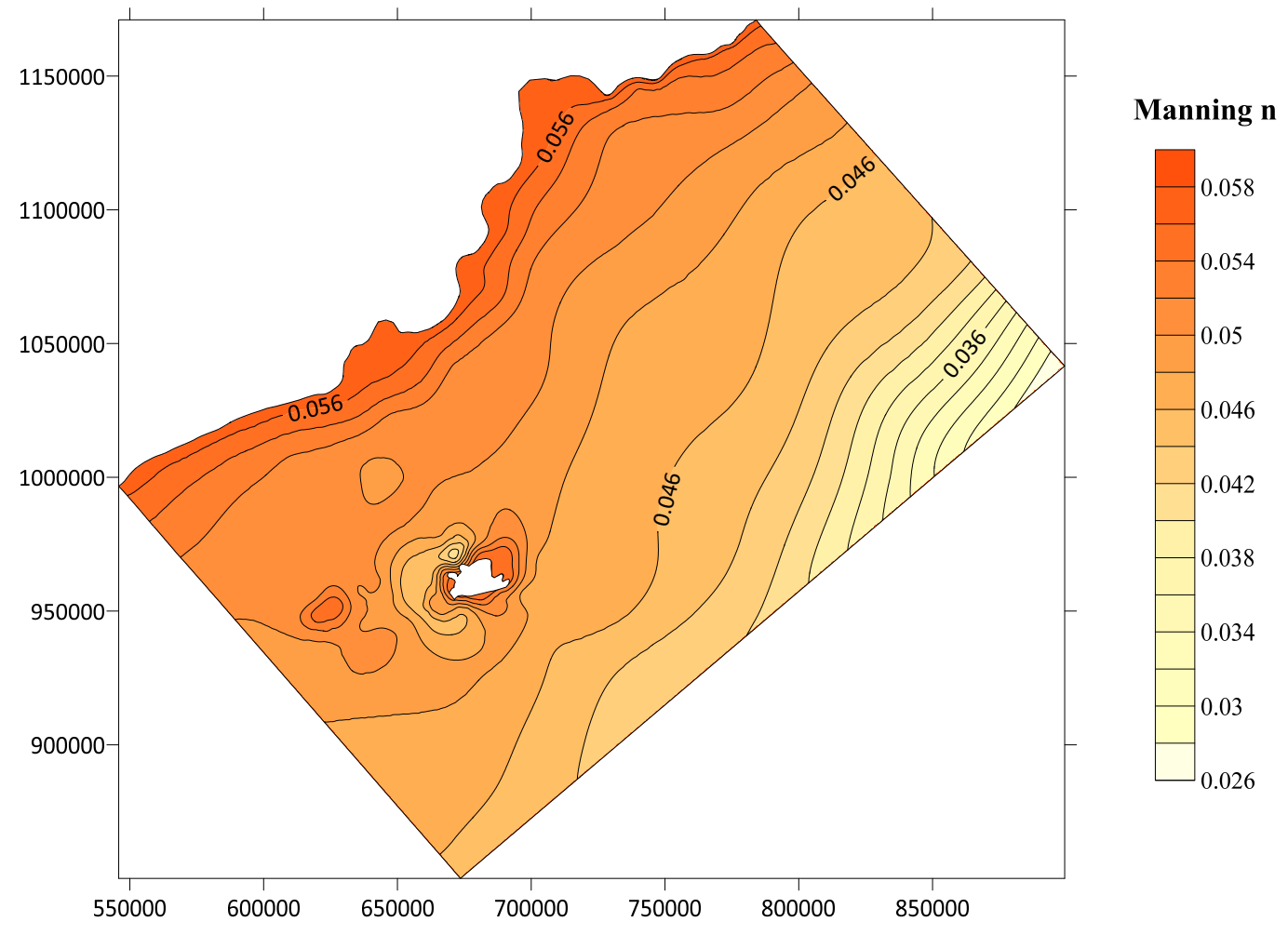

Figure 3. Roughness map.

Boundary conditions: The harmonic constant data for the four tidal constituents were extracted from the DTU10 Global Tide Model for the three open boundaries at sea. For river boundaries, the data is collected the Atlas Viet Nam (1994) for harmonic constant.

\subsection{The governing equations in the curvilinear coordinate system}

The governing equations in the curvilinear co-ordinates, are constructed based on the Reynolds equation in Cartesian coordinates [8]:

$$
\left\{\begin{array}{c}
p_{\tau}+g^{-1}\left(g_{22} \varsigma_{\xi}-g_{12} \varsigma_{\eta}\right)=\Psi_{1} \\
q_{\tau}+g H J^{-1}\left(g_{11} \varsigma_{\eta}-g_{12} \varsigma_{\xi}\right)=\Psi_{2} \\
J_{\tau}+p_{\xi}+q_{\eta}=0
\end{array}\right.
$$

where $\tau=\mathrm{t} ; \mathrm{p}=\mathrm{JUH} ; \mathrm{q}=\mathrm{JVH} ; \mathrm{H}=\mathrm{h}+\zeta$

$\mathrm{U}, \mathrm{V}$ are the "contravariant" base vectors of the curvilinear coordinate system.

$$
\begin{array}{cc}
\mathrm{U}=\mathrm{J}^{-1}\left(\mathrm{uy}_{\eta}-\mathrm{vx}_{\eta}\right) ; & \mathrm{V}=\mathrm{J}^{-1}\left(-\mathrm{vy}_{\xi}-\mathrm{vx}_{\xi}\right) \\
\Psi_{1}=\Psi_{\mathrm{a} 1}+\Psi_{\mathrm{t} 1}+\Psi_{\mathrm{k} 1} ; & \Psi_{2}=\Psi_{\mathrm{a} 2}+\Psi_{\mathrm{t} 2}+\Psi_{\mathrm{k} 2}
\end{array}
$$

$\Psi_{a_{1}}, \Psi_{\mathrm{a}_{2}}$ are the nonlinear component in curvilinear coordinate system $\xi, \eta$.

$\Psi_{\mathrm{t}_{1}}, \Psi_{\mathrm{t}_{2}}$ are the Friction bed component; $\Psi_{\mathrm{k}_{1}}, \Psi_{\mathrm{k}_{2}}$ are the Coriolis component. 


$$
\begin{gathered}
\Psi_{\mathrm{a} 1}=-\left[(\mathrm{pU})_{\xi}+(\mathrm{pV})_{\eta}+\mathrm{JH}\left(\mathrm{U}^{2} \Gamma_{11}^{1}+2 \mathrm{UV} \Gamma_{12}^{1}+\mathrm{V}^{2} \Gamma_{22}^{1}\right)\right\rfloor \\
\Psi_{\mathrm{a} 2}=-\left[(\mathrm{qU})_{\xi}+(\mathrm{qV})_{\eta}+\mathrm{JH}\left(\mathrm{U}^{2} \Gamma_{11}^{2}+2 \mathrm{UV} \Gamma_{12}^{2}+\mathrm{V}^{2} \Gamma_{22}^{2}\right)\right] \\
\Psi_{\mathrm{t} 1}=-\frac{\mathrm{K}}{\mathrm{H}}|\mathrm{v}| \mathrm{p} ; \quad \Psi_{\mathrm{t} 2}=-\frac{\mathrm{K}}{\mathrm{H}}|\mathrm{v}| \mathrm{q} ;
\end{gathered}
$$

$\Gamma_{\mathrm{i}, \mathrm{j}}^{\mathrm{k}}$ is the Christoffel symbol type - II is defined as follows: $\Gamma_{\mathrm{i}, \mathrm{j}}^{\mathrm{k}}=\frac{\partial \mathrm{e}_{\mathrm{i}}}{\partial \xi^{\mathrm{j}}} \mathrm{e}^{\mathrm{k}}$

$\mathrm{e}_{1}, \mathrm{e}_{2}$ are the base vectors of the curvilinear coordinate system $\xi, \eta$; ei, ei are the "covariant" base vectors $\overrightarrow{\mathrm{e}}$ [9-10].

The mesh is generated based on the Poisson equations (8) [11-12].

$$
\Delta^{2} \xi=\mathrm{P}(\xi, \eta) ; \quad \Delta^{2} \eta=\mathrm{Q}(\xi, \eta)
$$

where $\mathrm{P}$ and $\mathrm{Q}$ are the control functions. The solution of this equation system in the domain $(\xi, \eta)$ is:

$$
\mathrm{L}(\mathrm{r})=\mathrm{g}_{22} \mathrm{r}_{\xi \xi}-2 \mathrm{~g}_{12} \mathrm{r}_{\xi \eta}-\mathrm{g}_{11} \mathrm{r}_{\eta \eta}=-\mathrm{J}^{2}\left(\mathrm{Pr}_{\xi}+\mathrm{Qr}_{\eta}\right)
$$

$\mathrm{J}$ is the "Jacobian" of the transformation. $\mathrm{J}=\mathrm{x}_{\xi} \mathrm{x}_{\eta}+\mathrm{y}_{\xi} \mathrm{y}_{\eta} ; \quad 0 \neq \mathrm{J}<\infty$

$$
\begin{aligned}
& \mathrm{r}=\mathrm{x}_{\mathrm{i}}+\mathrm{y}_{\mathrm{j}} ; \quad \mathrm{g}_{22}=\mathrm{x}_{\eta}^{2}+\mathrm{y}_{\eta}^{2}=\left|\mathrm{r}_{\eta}\right|^{2} ; \\
& \mathrm{g}_{12}=\mathrm{x}_{\xi} \mathrm{x}_{\eta}+\mathrm{y}_{\xi} \mathrm{y}_{\eta}=\mathrm{r}_{\xi} \mathrm{r}_{\eta} ; \quad \mathrm{g}_{11}=\mathrm{x}_{\xi}^{2}+\mathrm{y}_{\xi}^{2}=\left|\mathrm{r}_{\xi}\right|^{2}
\end{aligned}
$$

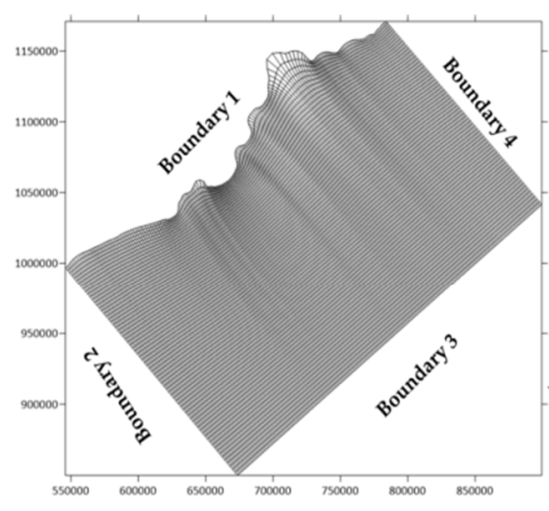

(a)

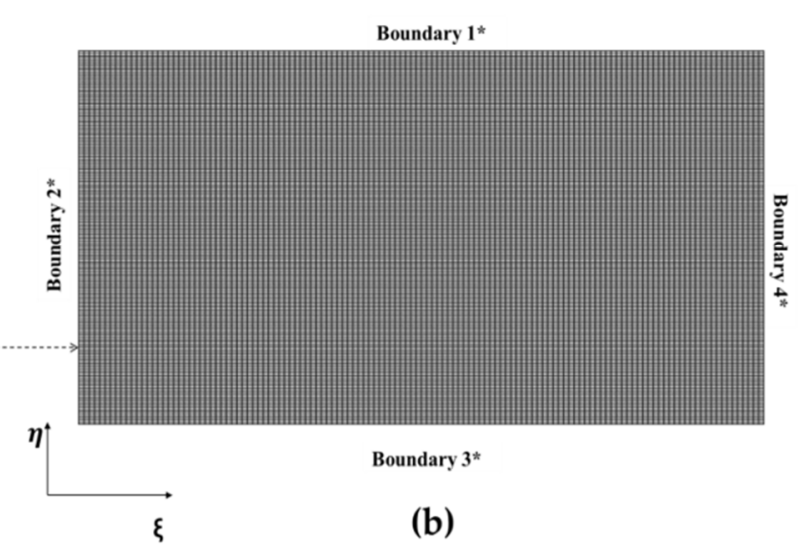

(b)

Figure 4. The mesh generation.

The study mesh (Figure 4) is a curved perpendicular mesh with a mesh size of $130 *$ 155 cells with $\mathrm{dx}$, dy in the range of 300 meters to 500 meters.

Boundary conditions: After setting up the hydraulic model (equation (1) and the mesh generation (equation (9)). The boundary conditions at the liquid boundaries give the form of oscillation of each tidal constituent $\left(\mathrm{K}_{1}, \mathrm{O}_{1}, \mathrm{M}_{2}\right.$ and $\left.\mathrm{S}_{2}\right)$, $\mathrm{g}_{\mathrm{o}}$ : Amplitude, frequency and phase of the tidal oscillation. The boundary conditions at the solid boundaries [12]: $p=0$ on $\xi=$ const and $q=0$ on $\eta=$ const.

Equation (4) are solved using alternating direction implicit method on C-Arakov grid. The mesh node is at the boundary, on which the velocity component is perpendicular to the boundary. In the algorithm, using the semi-implicit diagram: "gradient" the water level is calculated according to the implicit diagram, while the nonlinear component is solved by an explicit diagram $[8,9,14]$. 


\subsection{Energy balance equation}

In defining the energy in the study area, the total energy is a combination between kinetic energy and potential enery. These components are calculated in the below while two energy dissipation due to bottom friction and mesh smoothing is identify by using equations (13) [13].

$$
\begin{gathered}
K=\frac{1}{2} \rho \iint_{\Omega *} J^{-1} H^{-1} \mathbf{p}^{2} d \Omega * ; P=\frac{1}{2} \rho g \iint_{\Omega *} J \zeta^{2} d \Omega * \\
\mathrm{~W}_{\xi}=\rho \int_{\eta_{0}} \mathrm{q}\left(\frac{\mathrm{J}^{-2} \mathrm{H}^{-2} \mathbf{p}^{2}}{2}+\mathrm{g} \zeta\right) \mathrm{d} \xi \\
D_{1}=-K \rho \iint_{\Omega *} J^{-2} H^{-3} \mathbf{p}^{3} d \Omega * ; D_{2}=\frac{2}{d t} \iint_{\Omega *} \gamma\left[\boldsymbol{P}^{*} \nabla^{2} p+\boldsymbol{Q}^{*} \nabla^{2} q\right]
\end{gathered}
$$

where $\mathrm{K}$ is the Kinetic Energy; $\mathrm{P}$ is the potential energy; $\mathrm{W}$ is the energy flows across the liquid boundary; $\mathrm{D}_{1}$ is the velocity of energy dissipation due to bottom friction; $\mathrm{D}_{2}$ is the velocity of energy dissipation when smoothing; $\mathrm{P}^{*}, \mathrm{Q}^{*}$ are the "convariant" component of velocity vector.

$$
\boldsymbol{P}^{*}=g_{11} U+g_{12} V, \boldsymbol{Q}^{*}=g_{21} U+g_{22} V
$$

\section{Results}

\subsection{Verification model}

Total water level data of 4 constituents were extracted at My Thanh station from $10 \mathrm{pm}$ on $15 / 01 / 2017$ to $23 \mathrm{pm}$ on $14 / 02 / 2017$ (Figure 5) which the data is at Vung Tau station from $01 \mathrm{am}$ on $01 / 01 / 2017$ to $23 \mathrm{pm}$ on 28/02/2017 (Figure 6).

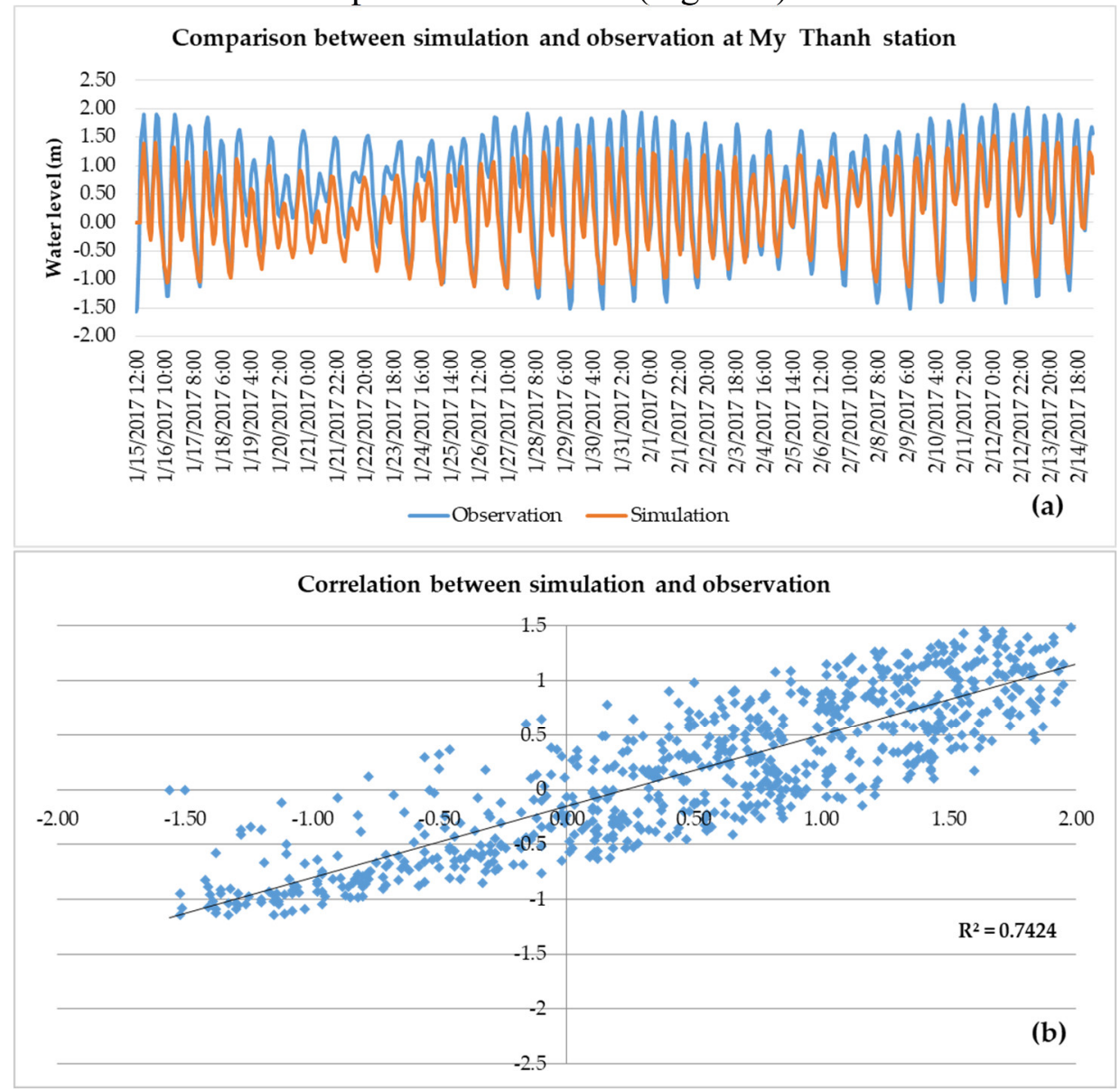

Figure 5. Comparison between simulation and observation at My Thanh station (a) and correlation between simulation and observation (b). 
The verifiable results of the water level at My Thanh and Vung Tau station show the correlation coefficient $\mathrm{R}^{2}=0.74, \mathrm{R}^{2}=0.64$ and $\mathrm{NSE}=0.6, \mathrm{NSE}=0.58$, respectively. The difference in amplitude can be explained that the water level data are extracted from the model is considered for 4 main constituents $\mathrm{M}_{2}, \mathrm{~K}_{1}, \mathrm{O}_{1}$ and $\mathrm{S}_{2}$, the others have not been considered. However, the phase of the water level is quite consistent with the observation data, which shows the great dominance of 4 constituents in this region.

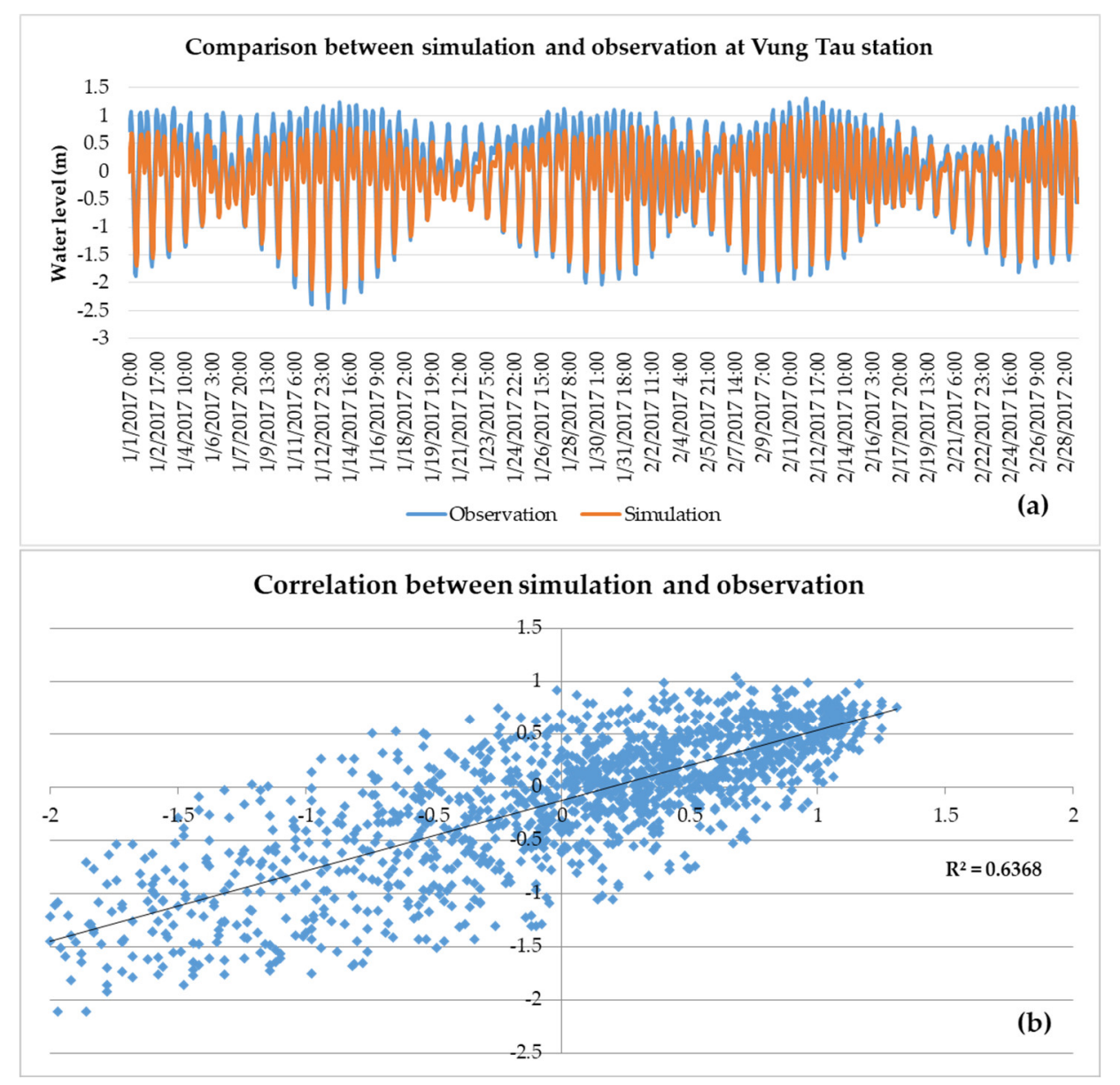

Figure 6. (a) Comparison between simulation and observation at Vung Tau station; (b) correlation between simulation and observation.

\subsection{Tidal constituents' energy}

The results showed that the energy variation (E: Total energy, P: Potential energy, K: Kinetic energy) of the semi-diurnal constituent $\mathrm{M}_{2}$ are the most important, followed by the tidal constituents $\mathrm{K}_{1}, \mathrm{O}_{1}$ and $\mathrm{S}_{2}$. As the coast of Hau Estuary is influenced by the mixed regime of semi-diurnal tides, the greatest tidal energy is $\mathrm{M}_{2}$, followed by the tidal constituents $\mathrm{K}_{1}, \mathrm{O}_{1}$ and $\mathrm{S}_{2}$.

The highest total energy of constituent $\mathrm{M}_{2}$ values about $6.6 \times 10^{10} \mathrm{KJ}$ (in which, the value of the potential energy is $4.3 \times 10^{10} \mathrm{KJ}$ while that of kinetic energy is lower, at about $4 \times 10^{10} \mathrm{KJ}$ ) (Figure 7). For the tidal constituents $\mathrm{S}_{2}$, the highest values of total energy $\mathrm{E}$, the potential energy $P$ and the kinetic energy are $0.82 \times 10^{10} \mathrm{KJ}, 0.58 \times 10^{10} \mathrm{KJ}$ and $0.42 \mathrm{x}$ $10^{10} \mathrm{KJ}$, respectively (Figure 7).

The results of energy balance are described by the results of variation in energy in the domain (Et), total energy across the liquid boundary (W), loss of energy caused by bottom friction $\left(D_{1}\right)$ and energy balance $((W+D)-E t)$. The obtained results are extracted within the period 9th of all four tidal constituents $\mathrm{M}_{2}, \mathrm{~S}_{2}, \mathrm{~K}_{1}$ and $\mathrm{O}_{1}$ in Figure 8. 


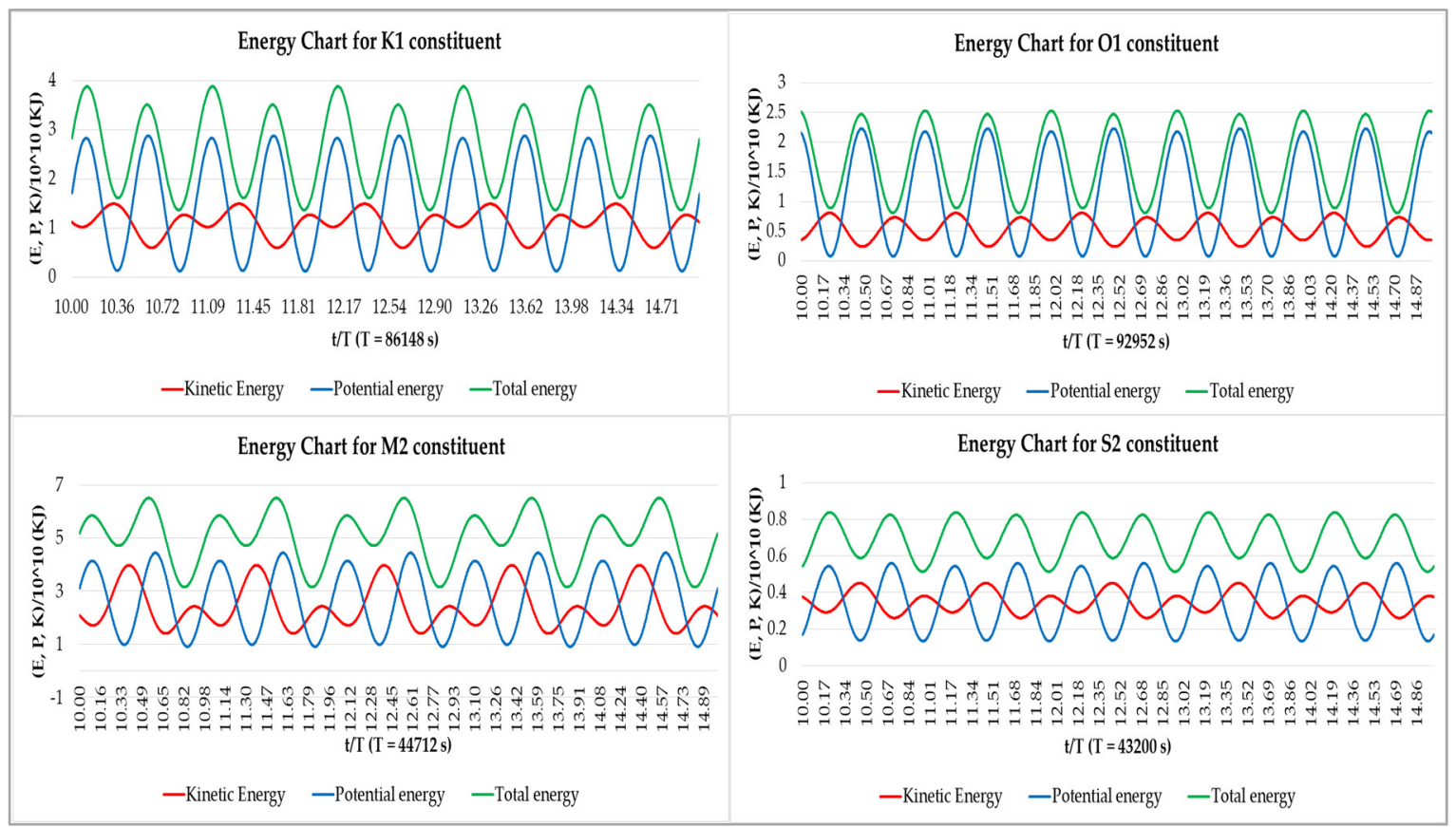

Figure 7. The simulation results of the energy of the constituents $\mathrm{K}_{1}, \mathrm{O}_{1}, \mathrm{M}_{2}$ and $\mathrm{S}_{2}$.

In general, the oscillations of the lines are sequences of sinusoidal. The oscillation of the total energy (W) and loss of energy caused by bottom friction $\left(\mathrm{D}_{1}\right)$ has an opposite phase while the total energy oscillates in phase with variation in energy in the domain $\left(E_{t}\right)$. The energy balance oscillation in the variable region around axis " 0 " represents the energy balance in the region. The homogeneity of the oscillation of the energy inflow in the region and the energy variation is substantial for all four constituents, and the energy loss because friction is virtually small.

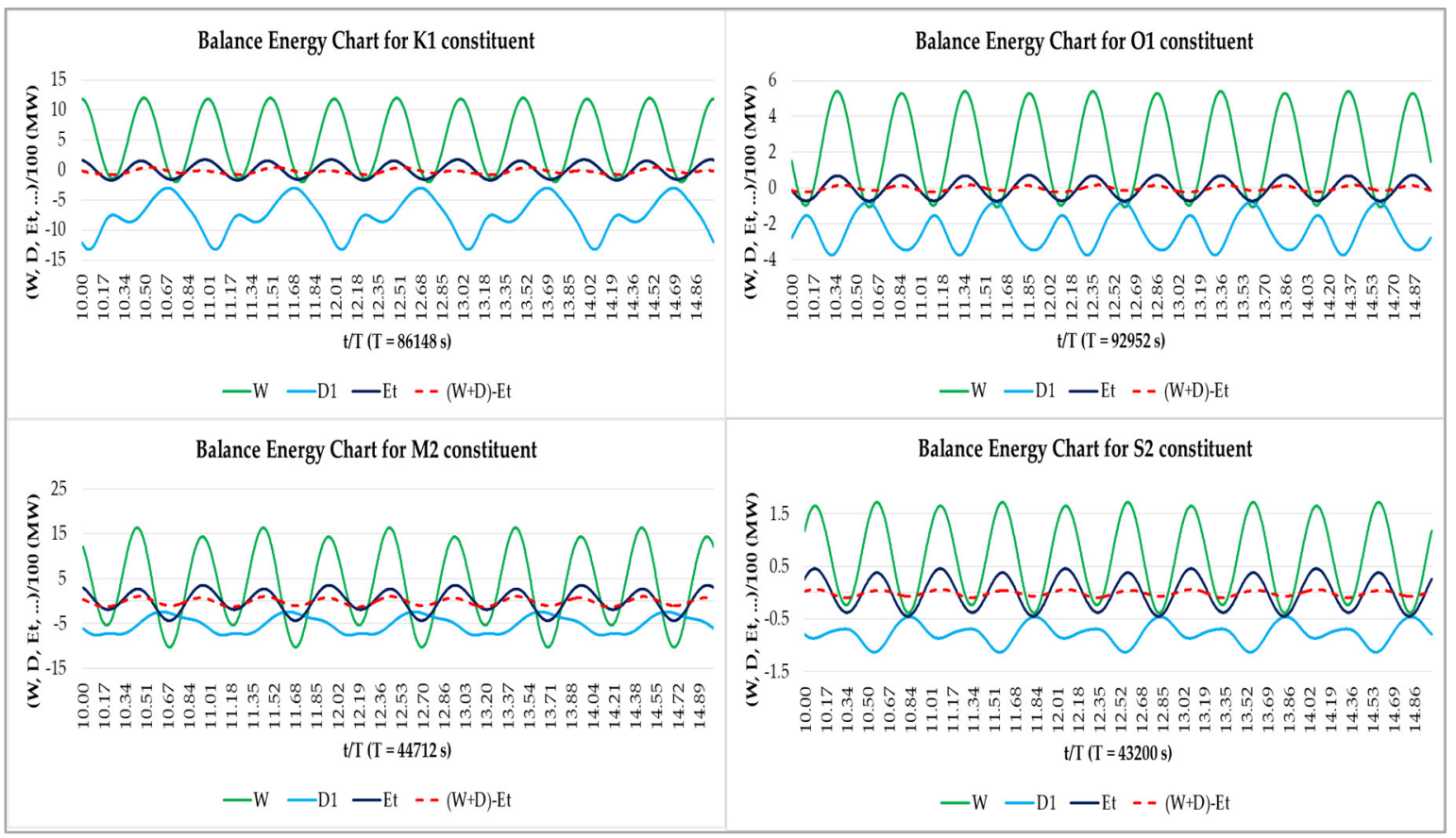

Figure 8. The simulation results of the tidal constituents energy balance: $K_{1}, \mathrm{O}_{1}, \mathrm{M}_{2}$ and $\mathrm{S}_{2}$ (The orange line represents the results of variation in energy in the domain $\left(\mathrm{E}_{t}\right)$, the green line is total energy across the liquid boundary (W), the blue line represents loss of energy caused by bottom friction $\left(D_{1}\right)$ and the red color is energy balance $\left((W+D)-E_{t}\right)$. 


\subsection{The tidal ellipse maps}

The residual tidal ellipse maps were constructed from the results of the amplitude and phase simulation of the four main tidal constituents: $\mathrm{K}_{1}, \mathrm{O}_{1}, \mathrm{M}_{2}$ and $\mathrm{S}_{2}$ (from $5^{\text {th }}$ period onwards). At the beginning of the periods $\left(1^{\text {th }}-5^{\text {th }}\right)$, the harmonic constituent oscillations are unstable. The ellipses of the diurnal constituent $K_{1}$ are quite small in size and the constituent has the most ellipses which are clockwise rotation in the 4 main constituents $\mathrm{K}_{1}$, $\mathrm{O}_{1}, \mathrm{M}_{2}$ and $\mathrm{S}_{2}$. From Vung Tau to Bac Lieu, these tidal ellipses change in both direction and magnitude, particularly in Tra Vinh coast. From Ba Ria-Vung Tau to Ben Tre, the tidal ellipses rotate clockwise direction with small sizes. However, in the Vung Tau coast, some tidal ellipses change direction but the tidal ellipse magnitude is unchanged. When reaching Tra Vinh coast, the ellipses change simultaneously direction (counterclockwise rotation) and the magnitude of the tidal ellipses increase. The ellipses rotate counter-clockwise from the coast of Tra Vinh to Bac Lieu (Figure 9). In particular, the coast of Soc Trang is a region full of tidal ellipses that rotate counterclockwise with a relatively large size (Figure $10)$.

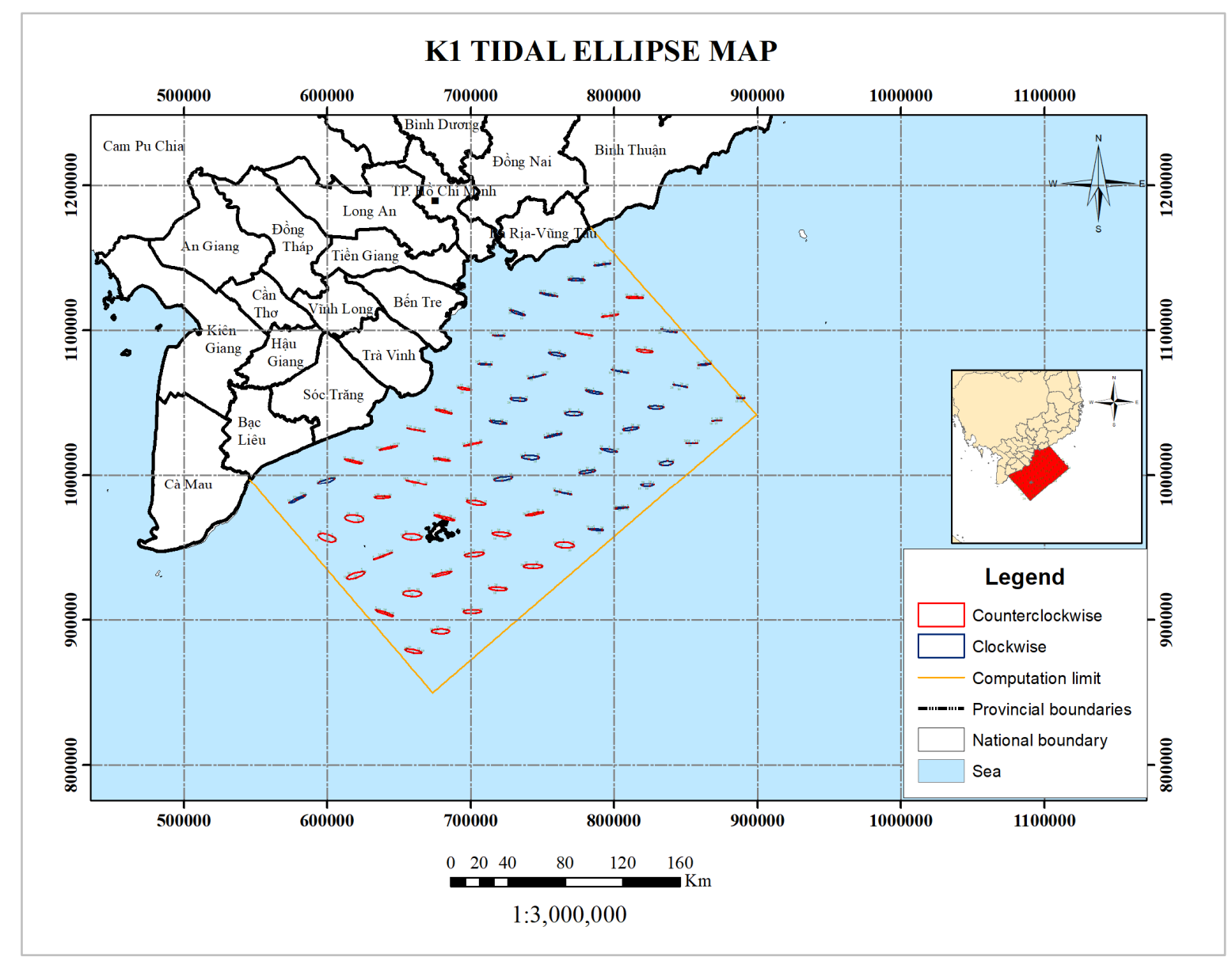

Figure 9. $\mathrm{K}_{1}$ tidal ellipse map.

Similar to the $\mathrm{K}_{1}$ diurnal constituent, the $\mathrm{O}_{1}$ diurnal constituent has tidal ellipses that vary in both direction and magnitude from Vung Tau to Bac Lieu and it has the smallest ellipses size in 4 main tidal constituents. The tidal ellipses from Vung Tau to Tra Vinh rotate mainly clockwise direction with small sizes. However, in the coastal area, only a few ellipses change their direction. From the coast of Tra Vinh to Bac Lieu, the tidal ellipses change simultaneously in both direction and magnitude. The tidal ellipses turn counterclockwise rotation and the magnitudes also increase significantly (Figure 11). In the 
coast of Soc Trang, ellipses rotate mainly in a counter-clockwise direction. But in the coast near the Hau estuary and a part of Vinh Chau, there are tidal ellipses that are opposite to the whole coast of Soc Trang but their size are small (Figure 12).

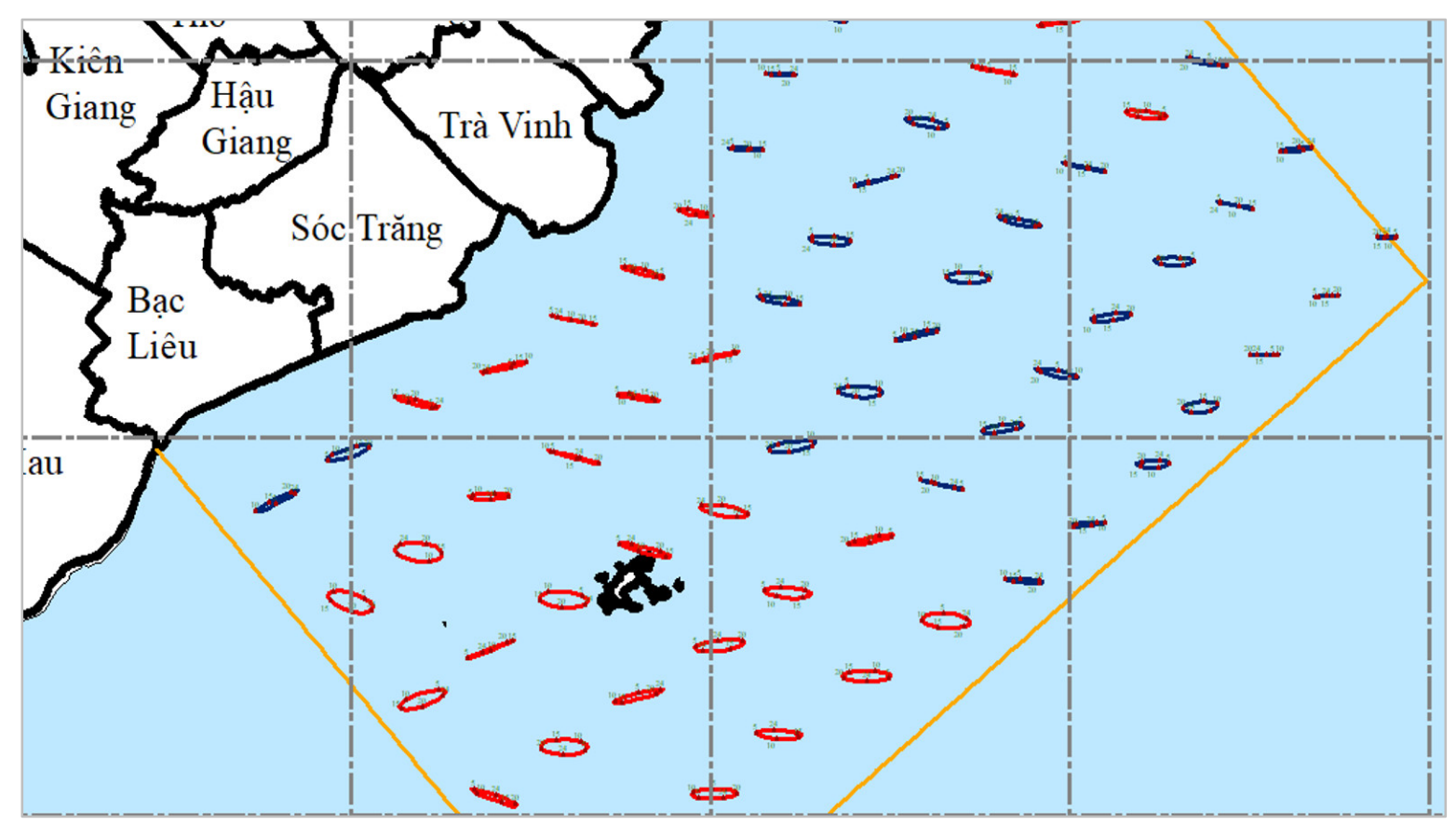

Figure 10. The tidal ellipse of $\mathrm{K}_{1}$ constituent in Soc Trang.

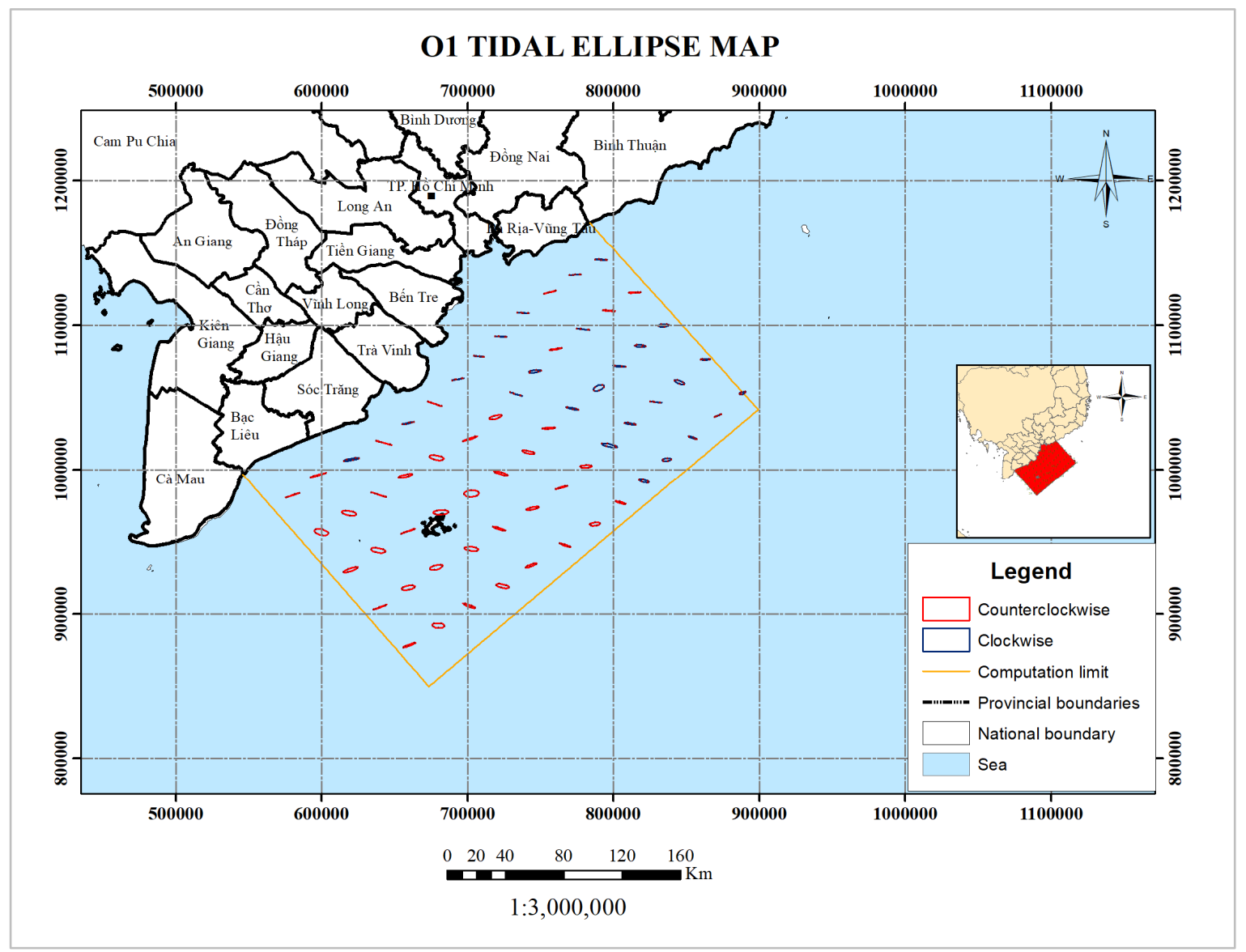

Figure 11. $\mathrm{O}_{1}$ tidal ellipse map. 


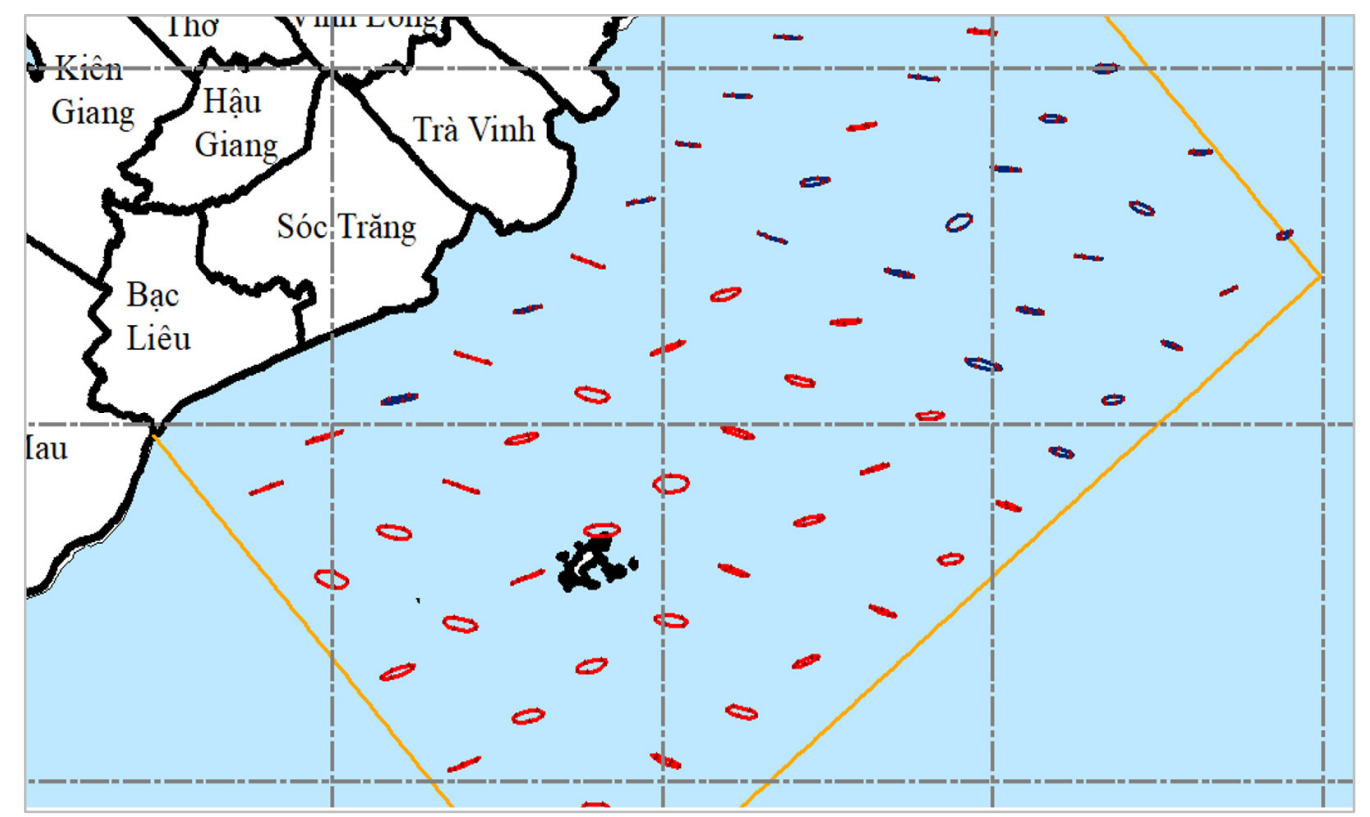

Figure 12. The tidal ellipse of $\mathrm{O}_{1}$ constituent in Soc Trang.

The $\mathrm{M}_{2}$ semi-diurnal constituent in the sea from Vung Tau to Bac Lieu is mainly ellipses rotating counterclockwise and it has the largest elliptical size in 4 main constituents. From Vung Tau to Ben Tre, the tidal ellipses change continuously direction with the tidal ellipses rotating clockwise (in the offshore zone) and counter-clockwise rotating ellipses (distributed mainly in the coastal area). From Tra Vinh to Bac Lieu, there are only counterclockwise tidal ellipses with large size (Figure 13). Similarly, Soc Trang coast is full of counterclockwise tidal ellipses with ellipse magnitude increasing as they are offshore, this is the area which has the largest tidal ellipse magnitude in whole calculation area (Figure 14).

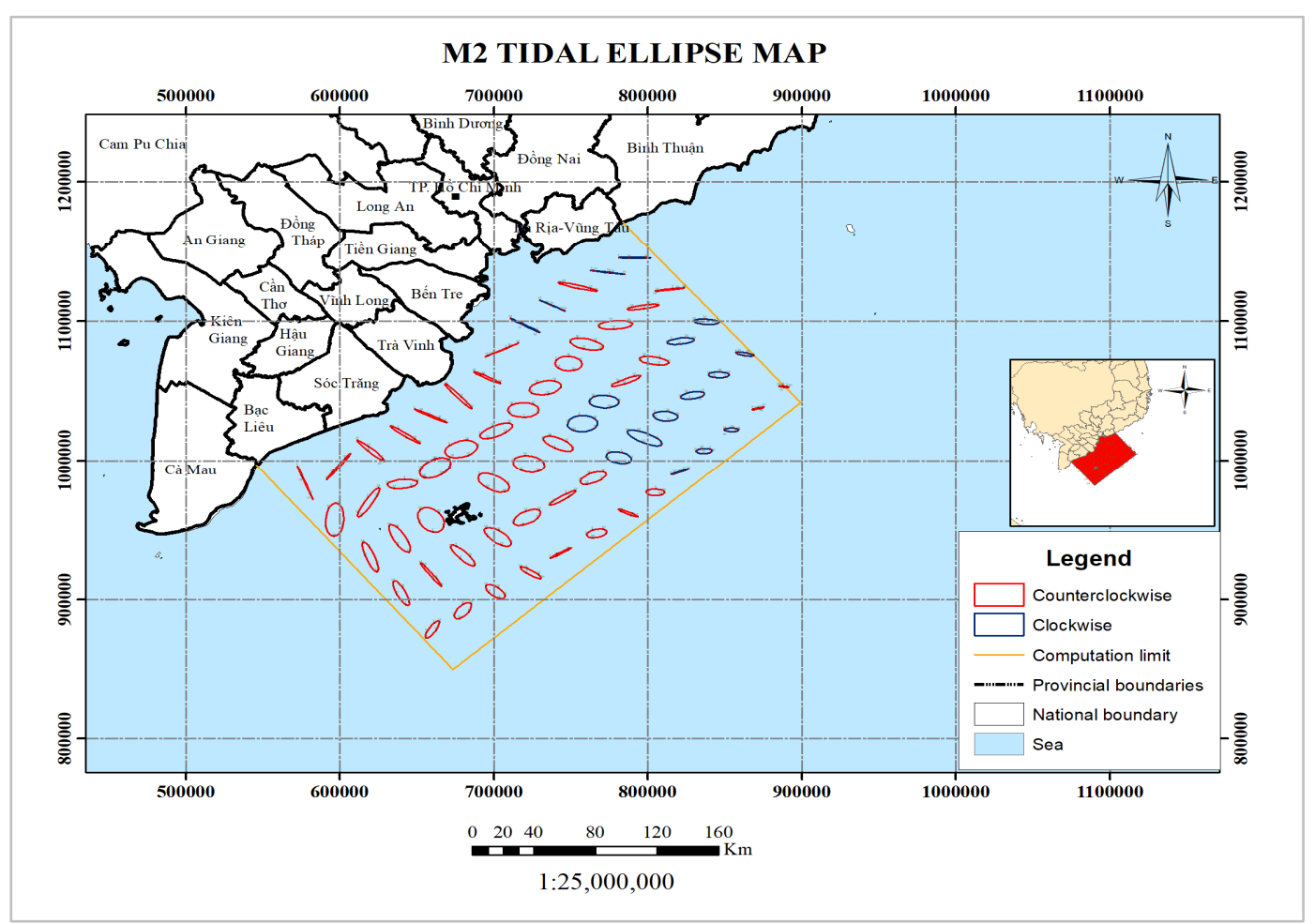

Figure 13. $\mathrm{M}_{2}$ tidal ellipse map. 


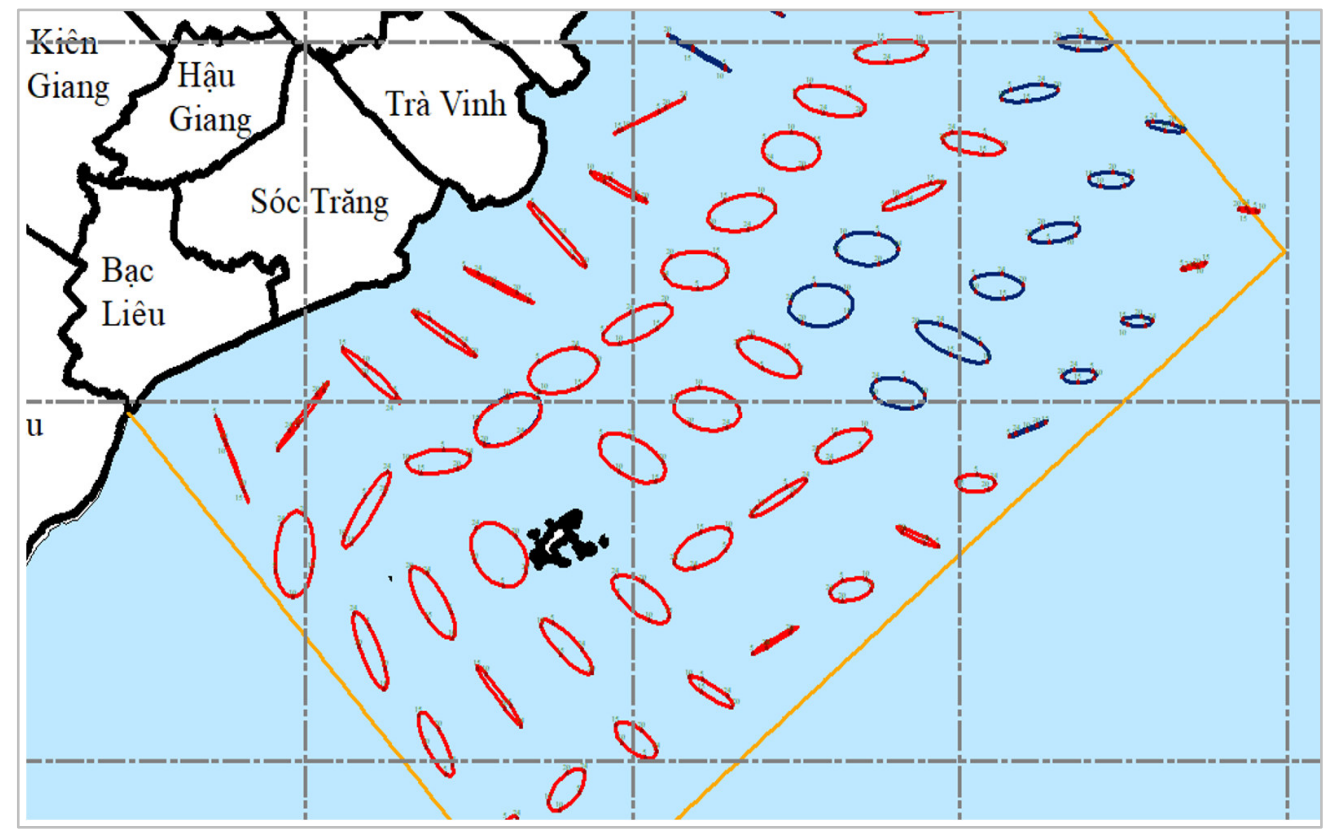

Figure 14. The tidal ellipse of $\mathrm{M}_{2}$ constituent in Soc Trang.

The $\mathrm{S}_{2}$ semi-diurnal constituent has some tidal ellipses that rotate counterclockwise and the ellipses are large in size, just smaller than the ellipse of $\mathrm{M}_{2}$ constituent. The tidal ellipses have large size at the center of the study area, at the East Sea boundaries, these ellipses are very small. This is the constituent that has the least quantity of ellipses rotating clockwise with a few tidal ellipses in the coast of Vung Tau, Ho Chi Minh City and Hau estuary (Figure 15). In the coast of Soc Trang, ellipses rotate mainly counterclockwise direction, but at the Hau estuary, the tidal ellipse changes in direction but does not change in magnitude (Figure 16).

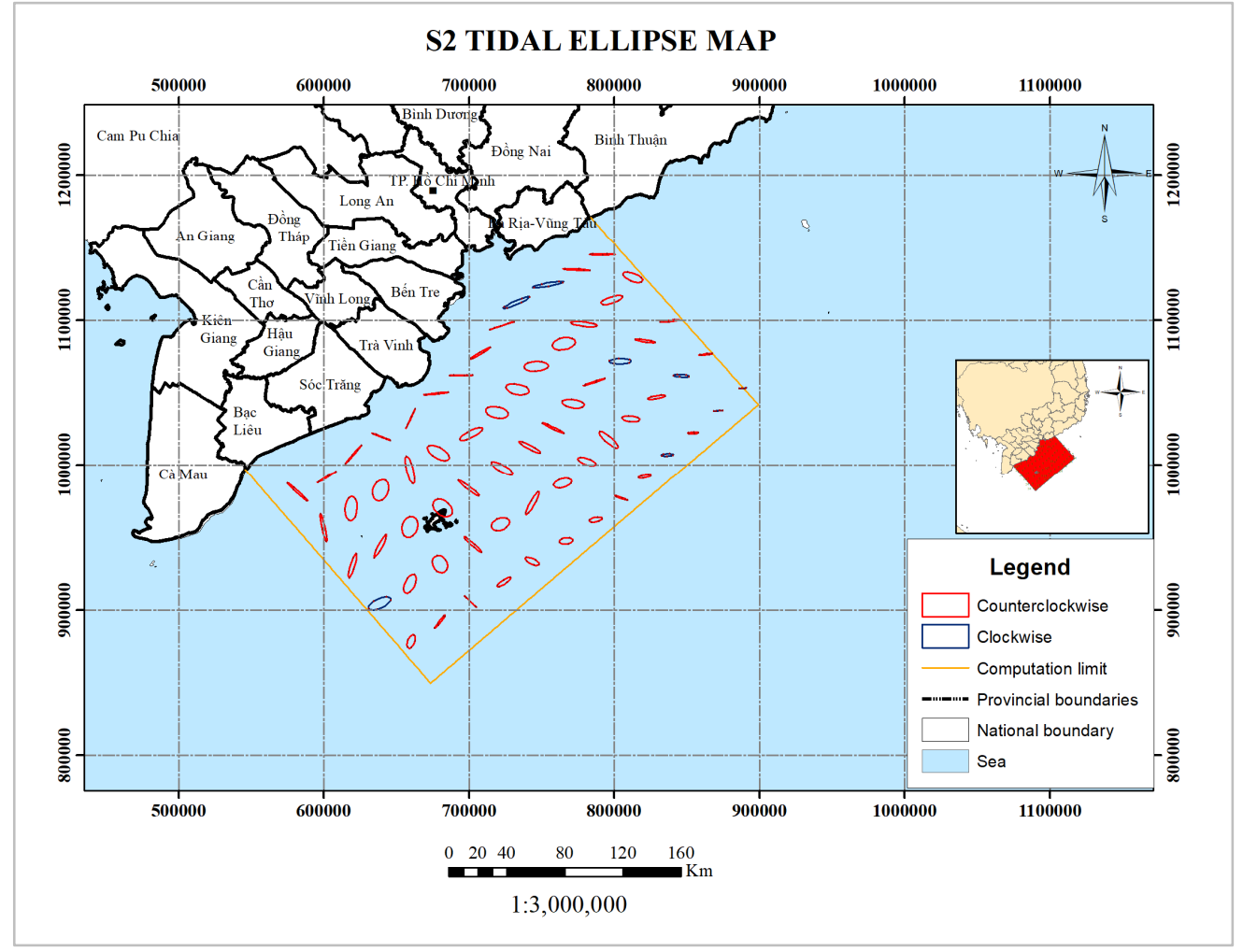

Figure 15. $\mathrm{S}_{2}$ tidal ellipse map. 


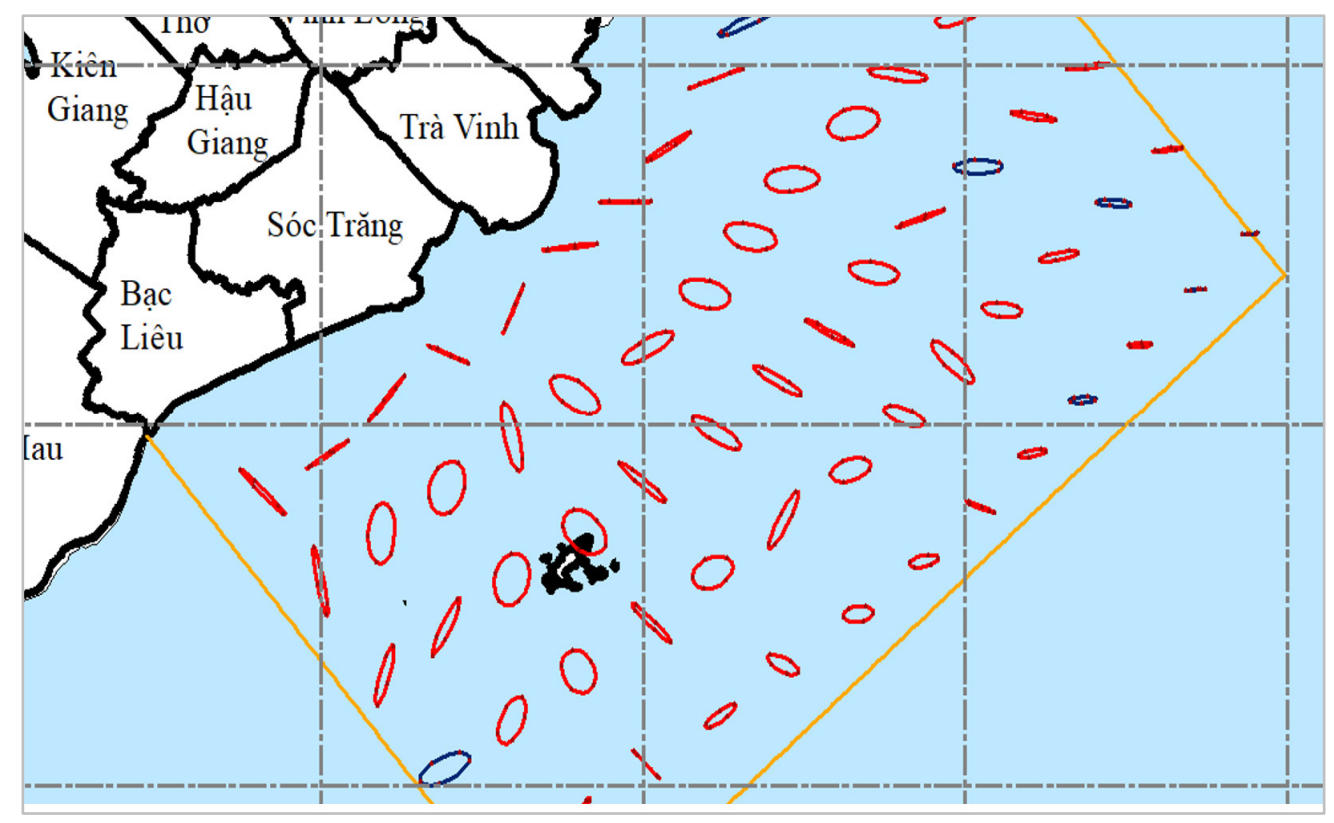

Figure 16. The tidal ellipse of $S_{2}$ constituent in Soc Trang.

\section{Conclusions}

In this paper, a hydraulic model in curvilinear coordinates was applied to build tidal ellipses for 4 main tidal constituents, namely $\mathrm{K}_{1}, \mathrm{O}_{1}, \mathrm{M}_{2}$ and $\mathrm{S}_{2}$ in a region from Vung TauBac Lieu, Viet Nam. The numerical method of this model derives from the solution of the Reynolds system of equations averaged over depths in the curvilinear coordinate systems. The model verification is implemented based on the equilibrium of the tidal currents of energy. The model is set up with the friction bed coefficients for four tidal constituents changing the water depth with the range of 0.026 to 0.058 . Generally, for coastal area from Vung Tau to Bac Lieu, the highest total energy of constituent $\mathrm{M}_{2}$ values about $6.6 \times 10^{10} \mathrm{KJ}$ (in which, the value of the potential energy is $4.3 \times 10^{10} \mathrm{KJ}$ while that of kinetic energy is lower, at about $4 \times 10^{10} \mathrm{KJ}$ ). For the tidal constituents $\mathrm{S}_{2}$, the highest values of total energy $\mathrm{E}$, the potential energy $\mathrm{P}$ and the kinetic energy are $0.82 \times 10^{10} \mathrm{KJ}, 0.58 \times 10^{10} \mathrm{KJ}$ and 0.42 $\mathrm{x} 10^{10} \mathrm{KJ}$, respectively. The oscillation of the total energy and loss of energy caused by bottom friction has an opposite phase while the total energy oscillates in phase with variation in energy in the domain. The homogeneity of the oscillation of the energy inflow in the region and the energy variation is substantial for all four constituents, and the energy loss because friction is virtually small.

The results recorded that the residual tidal ellipse $\mathrm{M}_{2}$ from Vung Tau-Bac Lieu, the greatest ellipses are $\mathrm{M}_{2}$, followed by the tidal constituents $\mathrm{K}_{1}, \mathrm{O}_{1}$ and $\mathrm{S}_{2}$. This rotation of the ellipse is almost the same with clockwise. The $\mathrm{S}_{2}$ semi-diurnal constituent has some tidal ellipses that rotate counterclockwise and the ellipses are large in size, just smaller than the ellipse of $\mathrm{M}_{2}$ constituent while these of the diurnal constituent $\mathrm{K}_{1}$ and $\mathrm{O}_{1}$ are quite small in size. In particular, the coast of Soc Trang is a region full of tidal ellipses that rotate counterclockwise with a relatively large size for of the diurnal constituent $\mathrm{K}_{1}$ and $\mathrm{O}_{1}$.

Author Contributions: Conceptualization, T.T.K., N.T.B.; Methodology, T.T.K., N.K.P., N.T.B.; Software, T.T.K., N.K.T.L.; Validation, N.T.T.H., N.K.T.L.; Formal analysis, T.T.K., N.K.T.L.; Investigation, P.T.M.D.; Resources, T.T.K., N.T.B.; Data curation, N.T.B., N.K.T.L.; Writing-original draft preparation, T.T.K., N.K.T.L.; Writing-review and editing, T.T.K., N.T.T.H., N.K.T.L; Visualization, T.T.K., N.K.T.L.; Supervision, N.K.P., N.T.B.; Project administration, N.K.P.; Funding acquisition, N.K.P. 
Funding: Tran Thi Kim was funded by Vingroup Joint Stock Company and supported by the Domestic Master/ PhD Scholarship Programme of Vingroup Innovation Foundation (VINIF), Vingroup Big Data Institute (VINBIGDATA).

Conflicts of Interest: The authors declare no conflict of interest.

\section{References}

1. Parker, B.B. Tidal analysis and prediction. Silver Spring, Maryland 2007, pp. 388.

2. $\mathrm{Xu}, \mathrm{Z}$. Ellipse parameters conversion and vertical velocity profiles for tidal currents. Bedford Institute of Oceanography, Dartmouth, Nova Scotia, Canada. 2000, pp. 20.

3. Stanton, B.R.; Goring, D.G.; Bell, R.G. Observed and modelled tidal currents in the New Zealand region. N. Z. J. Mar. Freshw. Res. 2001, 35(2), 397-415.

4. Dias, J.M.; Valentim, J.M. Numerical modeling of Tagus estuary tidal dynamics. $J$. Coast. Res. 2011, 64, 1495-1499.

5. Jung, K.Y.; Ro, Y.J.; Kim, B.J. Characteristics of tidal current and tidal residual current in the Chunsu Bay, Yellow Sea, Korea based on numerical modeling experiments. J. Korean Soc. Coast. Ocean Eng. 2013, 25(4), 207-218.

6 Mandal, S.; Sil, S.; Gangopadhyay, A.; Murty, T.; Swain, D. On extracting highfrequency tidal variability from HF radar data in the northwestern Bay of Bengal. $J$. Oper. Oceanogr. 2018, 11(2), 65-81.

7. Ahmed, S.N.; Siddiqa, T. The study of tidal current dynamics and impact of bathymetry in training the currents along the Coast of Karachi, Pakistan. Int. J. Marine Sci. Ocean Technol. 2019, 6(1), 110-116.

8. Long, B.H.; Chung, T.V. Caculations of tidal currents in the North Danger reef using finite element method. Proceedings of National Conference "Bien Dong 2007", 2007.

9. Phan, H.M.; Ye, Q.; Reniers, A.J.H.M.; Stive, M.J.F. Tidal wave propagation along The Mekong deltaic coast. Estuarine Coast. Shelf Sci. 2019, 220, 73-98.

10. Kim, T.T.; Long, N.K.T.; Phuoc, N.V.; Phung, N.K.; Bay, N.T. A coupled hydraulic and sediment transport model in the curvilinear coordinate. $V N J$. Hydrometeorol. 2021, 728, 14-30.

11. Androsov, A.A.; Klevanny, K.A.; Salusti, E.S.; Voltzinger, N.E. Open boundary conditions for horizontal 2-D curvilinear-grid long-wave dynamics of a strait. $A d v$. Water Resour. 1995, 18(5), 267-276.

12. Massel, S.R. Hydrodynamics of coastal zones. Amsterdam: Elsevier 1989, 48, 336.

13. Fletcher, C.A.J. Computational Techniques for Fluid Dynamics. Mir, Moscow 1991, 2. (Russian translation)

14. Thompson, J.F.; Warsi, Z.U.A.; Mastin, C.W. Numerical grid generation: Foundations and Applications. North-holland Amsterdam: Elsevier, 1985.

15. Bay, N.T.; Phung, N.K. Some study results for the tide in Tonkin gulf. Proceedings of the fourth National Conference of Marine science and technology. 1998.

16. Androsov, A.A.; Kagan, B.A.; Romanenkov, D.A.; Voltzinger, N.E. Numerical modelling of barotropic tidal dynamics in the strait of Messina. Adv. Water Resour. 2002, 25(4), 401-415. 